\title{
Verrucous Scalp Plaque and Widespread Eruption
}

Lauren L. Beal, BA; James Robert Duncan, MD; Peter G. Pavlidakey, MD; Tiffany Mayo, MD

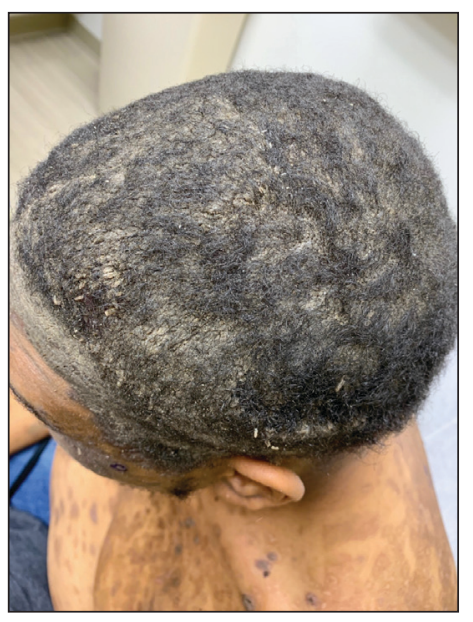

A 40-year-old Black man presented for evaluation of a thick plaque throughout the scalp (top), scaly plaques on the cheeks (bottom), and a spreading rash on the trunk that had progressed over the last few months. He had no relevant medical history, took no medications, and was in a monogamous relationship with a female partner. He previously saw an outside dermatologist who gave him triamcinolone cream, which was mildly helpful. Physical examination revealed a thick verrucous plaque throughout the scalp extending onto the forehead; thick plaques on the cheeks; and numerous, thinly eroded lesions on the trunk. Biopsies and a laboratory workup were performed.

\section{WHAT'S YOUR DIAGNOSIS?}
a. disseminated blastomycosis
b. hypertrophic lupus erythematosus
c. pemphigus foliaceous
d. sebopsoriasis
e. secondary syphilis

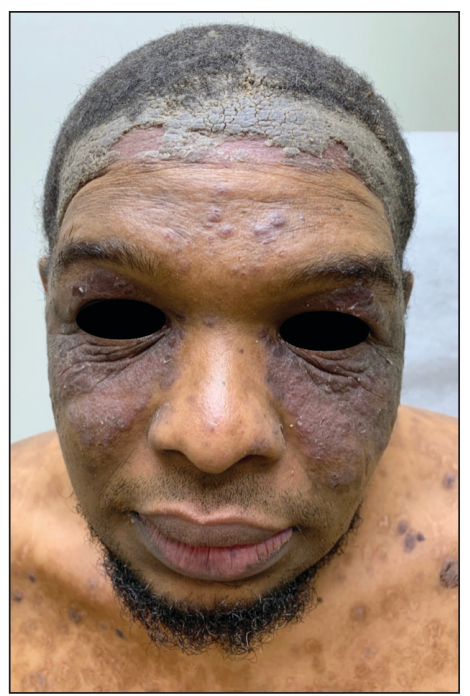

PLEASE TURN TO PAGE E37 FOR THE DIAGNOSIS

Ms. Beal is from the School of Medicine, McGovern Medical School at UTHealth, Houston, Texas. Drs. Duncan, Pavlidakey, and Mayo are from the Department of Dermatology, University of Alabama, Birmingham.

The authors report no conflict of interest.

Correspondence: Lauren L. Beal, BA, McGovern Medical School at UTHealth, School of Medicine, 6431 Fannin St, Houston, TX 77030 (lauren.I.beal@uth.tmc.edu).

doi:10.12788/cutis.0349 


\section{THE DIAGNOSIS: Pemphigus Foliaceous}

aboratory workup including a complete blood cell count with differential, comprehensive metabolic - panel, antinuclear antibodies, Sjögren syndrome A and $\mathrm{B}$ antibodies, hepatitis profile, rapid plasma reagin, HIV screen, aldolase, anti-Jo-1, T-Spot TB test (Quest Diagnostics), and tissue cultures was unremarkable. Two 4-mm punch biopsies were obtained from the left cheek and upper back, both of which demonstrated intragranular acantholysis suggestive of pemphigus foliaceous (Figure 1A). A subsequent punch biopsy from the right lower abdomen sent for direct immunofluorescence demonstrated netlike positivity of $\operatorname{IgG}$ and $\mathrm{C} 3$ in the upper epidermis (Figure 1B), and serum sent for indirect immunofluorescence demonstrated intercellular IgG antibodies to desmoglein (Dsg) 1 on monkey esophagus and positive Dsg-1 antibodies on enzyme-linked immunosorbent assay, confirming the diagnosis.
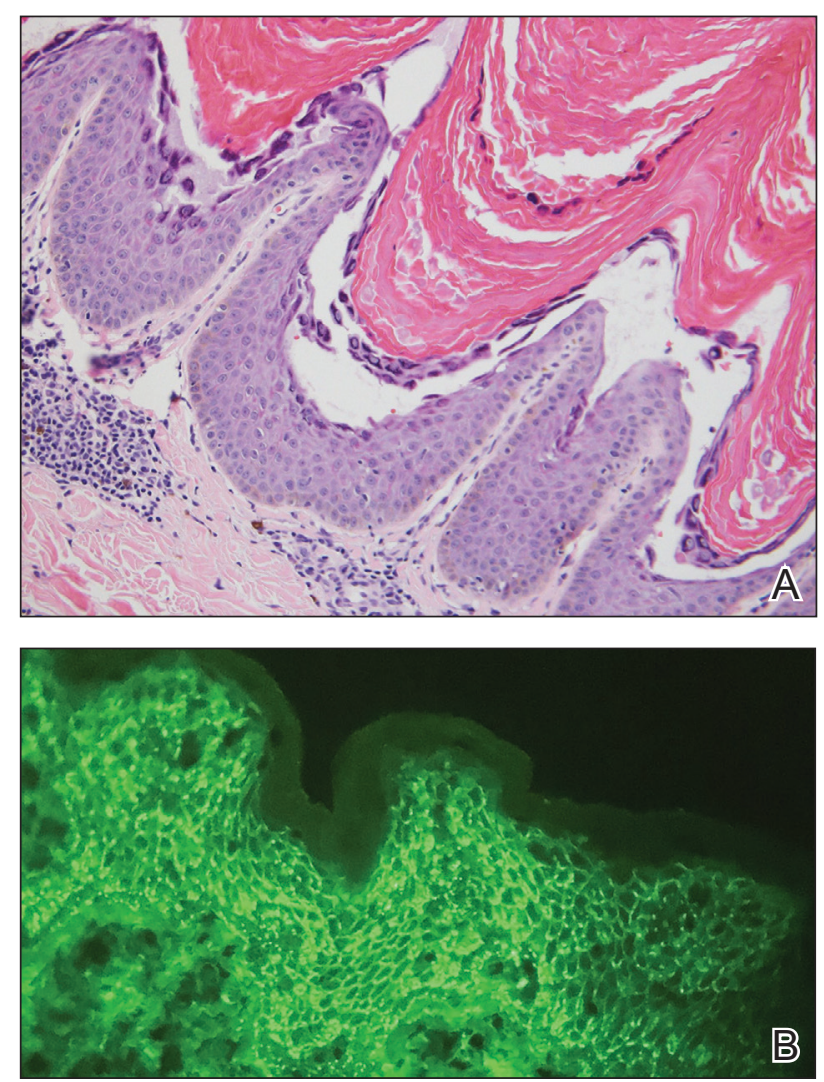

FIGURE 1. A, Intragranular acantholysis with superficial blister formation $(H \& E$, original magnification $\times 20)$. B, Netlike pattern of intercellular IgG and C3 in the upper portions of the epidermis on direct immunofluorescence (original magnification $\times 20$ ).
The patient was started on a 60 -mg prednisone taper as well as dapsone $50 \mathrm{mg}$ daily; the dapsone was titrated up to $100 \mathrm{mg}$ daily. After tapering down to $10 \mathrm{mg}$ daily of prednisone over 2 months and continuing dapsone with minimal improvement, he was given 2 infusions of rituximab $1000 \mathrm{mg} 2$ weeks apart. The scalp plaque was dramatically improved at 3-month follow-up (Figure 2), with partial improvement of the cheek plaques (Figure 3). Dapsone was increased to $150 \mathrm{mg}$ daily, and he was encouraged to use triamcinolone acetonide ointment $0.1 \%$ twice daily, which led to further improvement.

Pemphigus foliaceus is an autoimmune blistering disease that most commonly occurs in middle-aged adults. It generally is less common than pemphigus vulgaris, except in Finland, Tunisia, and Brazil, where there is an endemic condition with an identical clinical and histological presentation known as fogo selvagem. ${ }^{1}$

The pathogenesis of pemphigus foliaceous is characterized by IgG autoantibodies against Dsg-1, a transmembrane glycoprotein involved in the cellular adhesion of keratinocytes, which is preferentially expressed in the superficial epidermis. ${ }^{2-7}$ Dysfunction of Dsg-1 results in the separation of superficial epidermal cells, resulting in intraepidermal blisters. ${ }^{2,7}$ In contrast to pemphigus vulgaris, there typically is a lack of oral mucosal involvement due to compensation by Dsg-3 in the mucosa. ${ }^{4}$ Potential triggers for pemphigus foliaceous include exposure to UV radiation; radiotherapy;

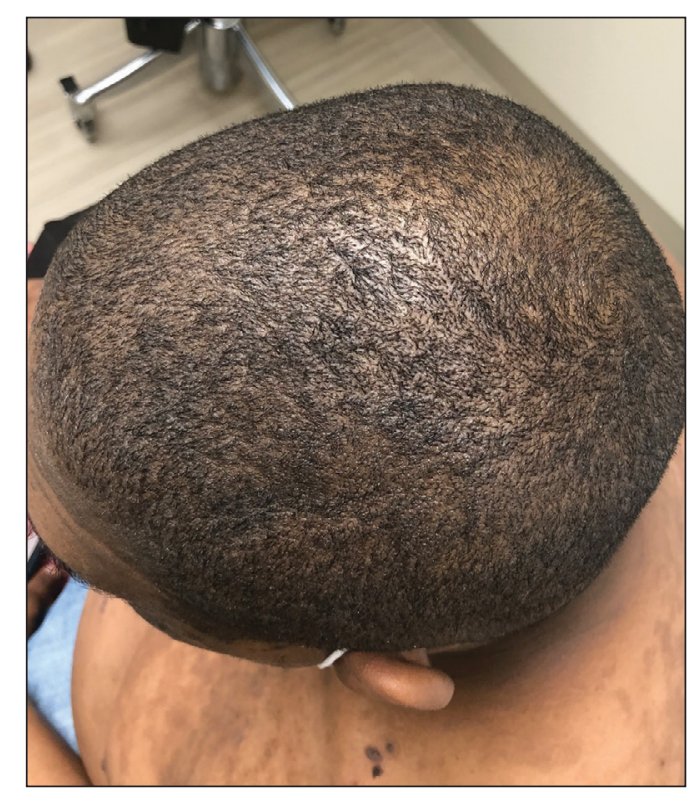

FIGURE 2. Substantial improvement of the verrucous scalp plaque 3 months after rituximab infusion. 


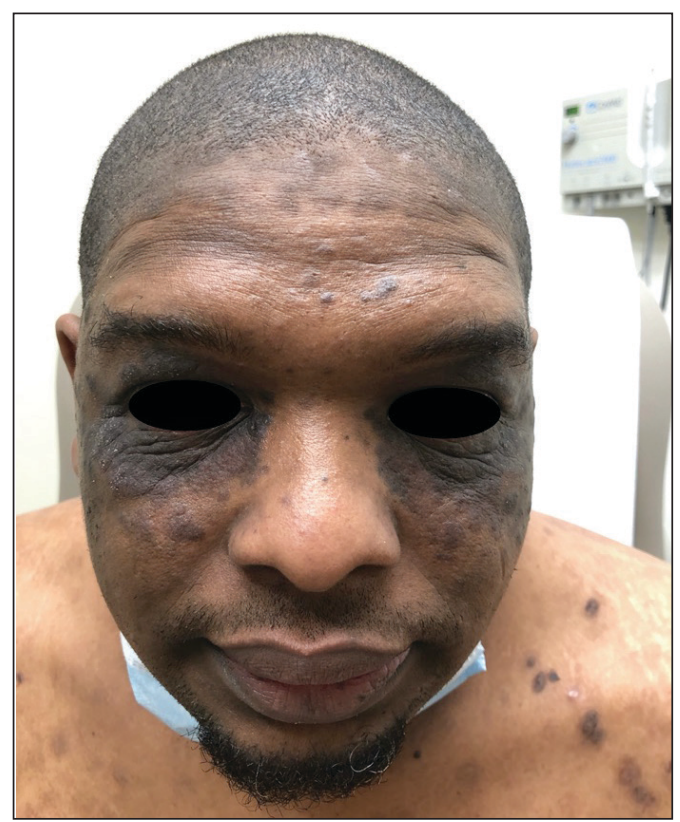

FIGURE 3. Partial improvement of facial plaques 3 months after rituximab infusion.

pregnancy; physiologic stress; and drugs, most commonly captopril, penicillamine, and thiols. ${ }^{8}$

Pemphigus foliaceous lesions clinically appear as eroded and crusted lesions on an erythematous base, commonly in a seborrheic distribution on the face, scalp, and trunk with sparing of the oral mucosa, ${ }^{2,6}$ but lesions can progress to a widespread and more severe exfoliative dermatitis. ${ }^{7}$ Lesions also can appear as psoriasiform plaques and often are initially misdiagnosed as psoriasis, particularly in patients with skin of color. 9,10

Diagnosis of pemphigus foliaceous typically is made using a combination of histology as well as both direct and indirect immunofluorescence. Histologically, pemphigus foliaceus presents with subcorneal acantholysis, which is most prominent in the granular layer and occasionally the presence of neutrophils and eosinophils in the blister cavity. ${ }^{7}$ Direct immunofluorescence demonstrates netlike intercellular IgG and C3 in the upper portion of the epidermis. ${ }^{11}$ Indirect immunofluorescence can help detect circulating IgG antibodies to Dsg-1, with guinea pig esophagus being the ideal substrate. ${ }^{11,12}$

First-line treatment of pemphigus foliaceus consists of systemic glucocorticoid therapy, often administered with azathioprine, methotrexate, or mycophenolate mofetil. ${ }^{2,6,13}$ Although first-line treatment is effective in $60 \%$ to $80 \%$ of patients, $^{2}$ relapsing cases can be treated with cyclophosphamide, intravenous immunoglobulin, immunoadsorption, plasmapheresis, or rituximab. ${ }^{2}$

Rituximab is a chimeric monoclonal antibody targeting CD20 ${ }^{+} \mathrm{B}$ cells, leading to decreased antibody production, which has been shown to be effective in treating severe and refractory cases of pemphigus foliaceus. ${ }^{6,13}$
Rituximab with short-course prednisone has been found to be more effective in achieving complete remission at 24 months than prednisone alone. ${ }^{14}$ In patients with contraindications to systemic glucocorticoid therapy, rituximab has been shown as an effective first-line therapy. ${ }^{15}$ One-quarter of patients treated with rituximab relapsed within 2 years of treatment ${ }^{6}$ (average time to relapse, 6-26 months). ${ }^{16}$ High-dose rituximab regimens, along with a higher number of rituximab treatment cycles, have been shown to prolong time to relapse. ${ }^{6}$ Further, higher baseline levels of Dsg-1 antibody have been correlated to earlier relapse and can be used following rituximab therapy to monitor disease progression. ${ }^{6,16}$

The differential diagnosis for pemphigus foliaceous includes disseminated blastomycosis, hypertrophic lupus erythematosus, sebopsoriasis, and secondary syphilis. Disseminated blastomycosis presents with cutaneous manifestations such as nodules, papules, or pustules evolving over weeks to months into ulcers with subsequent scarring. ${ }^{17}$ Hypertrophic lupus erythematosus presents with papules and nodules with associated keratotic scaling on the face, palms, and extensor surfaces of the limbs. ${ }^{18}$ Sebopsoriasis is characterized by well-defined lesions with an overlying scale distributed on the scalp, face, and chest. ${ }^{19}$ Secondary syphilis presents as early hyperpigmented macules transitioning to acral papulosquamous lesions involving the palms and soles. ${ }^{20}$

\section{REFERENCES}

1. Hans-Filho G, Aoki V, Hans Bittner NR, et al. Fogo selvagem: endemic pemphigus foliaceus. An Bras Dermatol. 2018;93:638-650.

2. Jenson KK, Burr DM, Edwards BC. Case report: reatment of refractory pemphigus foliaceus with rituximab. Practical Dermatology. February 2016:33-36. Accessed August 27, 2021. https://practicaldermatology.com/articles/2016-feb/case-report -treatment-of-refractory-pemphigus-foliaceus-with-rituximab -financial-matters-aad-asds-resources

3. Amagai M, Hashimoto T, Green KJ, et al. Antigen-specific immunoadsorption of pathogenic autoantibodies in pemphigus foliaceus. J Invest Dermatol. 1995;104:895-901.

4. Mahoney MG, Wang Z, Rothenberger K, et al. Explanations for the clinical and microscopic localization of lesions in pemphigus foliaceus and vulgaris. J Clin Invest. 1999;103:461-468.

5. Oktarina DAM, Sokol E, Kramer D, et al. Endocytosis of IgG, desmoglein 1, and plakoglobin in pemphigus foliaceus patient skin. Front Immunol. 2019;10:1-12.

6. Kraft M, Worm M. Pemphigus foliaceus-repeated treatment with rituximab 7 years after initial response: a case report. Front Med. 2018;5:315.

7. Hale EK. Pemphigus foliaceous. Dermatol Online J. 2002;8:9.

8. Tavakolpour S. Pemphigus trigger factors: special focus on pemphigus vulgaris and pemphigus foliaceus. Arch Dermatol Res. 2018;310:95-106.

9. A boobaker J, Morar N, Ramdial PK, et al. Pemphigus in South Africa. Int J Dermatol. 2001;40:115-119.

10. Austin E, Millsop JW, Ely H, et al. Psoriasiform pemphigus foliaceus in an African American female: an important clinical manifestation. J Drugs Dermatol. 2018;17:471.

11. Arbache ST, Nogueira TG, Delgado L, et al. Immunofluorescence testing in the diagnosis of autoimmune blistering diseases: overview of 10-year experience. An Bras Dermatol. 2014;89:885-889.

12. Sabolinski ML, Beutner EH, Krasny S, et al. Substrate specificity of antiepithelial antibodies of pemphigus vulgaris and pemphigus foliaceus sera in immunofluorescence tests on monkey and guinea pig esophagus sections. J Invest Dermatol. 1987;88:545-549. 
13. Palacios-Álvarez I, Riquelme-McLoughlin C, Curto-Barredo L, et al. Rituximab treatment of pemphigus foliaceus: a retrospective study of 12 patients. J Am Acad Dermatol. 2021;85:484-486.

14. Murrell DF, Sprecher E. Rituximab and short-course prednisone as the new gold standard for new-onset pemphigus vulgaris and pemphigus foliaceus. Br J Dermatol. 2017;177:1143-1144.

15. Gregoriou S, Efthymiou O, Stefanaki C, et al. Management of pemphigus vulgaris: challenges and solutions. Clin Cosmet Investig Dermatol. 2015;8:521-527.

16. Saleh MA. A prospective study comparing patients with early and late relapsing pemphigus treated with rituximab. J Am Acad Dermatol. 2018;79:97-103.
17. Castillo CG, Kauffman CA, Miceli MH. Blastomycosis. Infect Dis Clin North Am. 2016;30:247-264

18. Herzum A, Gasparini G, Emanuele C, et al. Atypical and rare forms of cutaneous lupus erythematosus: the importance of the diagnosis for the best management of patients. Dermatology. 2013;1-10.

19. Tull TJ, Noy M, Bunker CB, et al. Sebopsoriasis in patients with HIV: a case series of 20 patients. Br J Dermatol. 2016; 173:813-815

20. Balagula Y, Mattei P, Wisco OJ, et al. The great imitator revised: the spectrum of atypical cutaneous manifestations of secondary syphilis. Int J Dermatol. 2014;53:1434-1441. 